Editoriais / Editorials

\section{Anemia falciforme. Objetivos e resultados no tratamento de uma doença de saúde pública no Brasil}

\section{Sickle cell disease. Aims and results in the treatment of a health public disease in Brazil}

Milton A. Ruiz

Neste fascículo organizado e conduzido pelo co-editor Rodolfo Delfini Cançado, produto de um evento de grande repercussão nacional sobre anemia falciforme, discutem-se as várias nuances clínicas e hematológicas sobre o tema.

A anemia falciforme, do ponto de vista histórico, é do conhecimento da humanidade desde os tempos imemoriais e constatadas como secular na África pelo hábito existente em diversas tribos do continente de tatuar os portadores e os pacientes para identificar a doença. O primeiro relato em relação à doença ocorreu nos Estados Unidos da América em necropsias de pacientes nos quais se identificou agenesia esplênica em afro-americano com antecedentes clínicos crônicos similares ao da anemia falciforme. ${ }^{1} \mathrm{O}$ primeiro relato científico sobre a anemia falciforme foi descrita por Herrick, em 1910, em um estudante da Universidade das Índias Ocidentais, proveniente de Granada, na América Central, no qual se observou, à microscopia, o aspecto anômalo e alongado das hemácias. ${ }^{2}$

A introdução da hemoglobina S, responsável pela anemia falciforme no Brasil, deu-se através do tráfico de escravos de inúmeras tribos africanas, tráfico este iniciado em 1550 e suspenso oficialmente em 1850, para trabalho escravo na indústria da cana-de-açúcar do Nordeste e, posteriormente, para a lavra do ouro e extração de metais preciosos em Minas Gerais. A partir da abolição da escravatura, o fluxo migratório se expandiu para várias regiões do país e iniciouse a panmixia racial, que hoje é uma característica do nosso país.

A contribuição da comunidade científica nacional no estudo da anemia falciforme e das hemoglobinopatias sempre foi um marco. Desde a definição da base genética realizada por $\mathrm{Neel}^{3}$ e Accioly ${ }^{4}$ independentemente, enfatizada por Azevedo ${ }^{5}$ em sua carta de retratação histórica, aos trabalhos de levantamento da freqüência da doença como o realizado em internados da Santa Casa de Misericórdia de Santos efetuado por Boturão. ${ }^{6}$

Nas décadas que se seguiram, vários estudos caracterizaram o perfil da anemia falciforme no Brasil, e o rastreamento da moléstia pode ser comprovado através das publicações e teses acadêmicas que se seguiram, realizadas nas diversas instituições brasileiras, o que atestou o engajamento científi- co da hematologia brasileira no estudo das hemoglobinopatias. $^{7-10}$

Na seqüência reproduzo o texto de apresentação da tese "Prevalência de hemoglobinas anormais em recém-nascidos na cidade de Santos, São Paulo, de 1985": ${ }^{11}$

"Este trabalho foi realizado a partir de observações iniciais do amigo, já falecido, Carlos Zindell, obstetra da Casa de Saúde de Santos, que alertava sobre a incidência de processos infecciosos em gestantes negróides e da necessidade de se pesquisar hemoglobinopatia $S$.

Em 1980, o nosso interesse pela deteç̧ão precoce de hemoglobinopatias em berçários e em gestantes negróides se concretizou com a organização do presente trabalho.

A programação e as linhas gerais do trabalho foram apresentadas a inúmeros hospitais da cidade de Santos, recebendo plena receptividade e aceitação pelas diretorias dos hospitais contatados. Logo este entusiasmo desapareceu e a obtenção do sangue de recém-nascidos para análise sofreu inúmeros problemas e restrições. Constatamos então, durante todo este tempo, o desconhecimento acerca das doenças hereditárias mais freqüentes em nosso meio pela classe médica, além de uma visão social distorcida destes problemas.

O preconceito foi outro dos fatores que dificultaram a execução do trabalho pelo sentimento racial existente quanto à anemia falciforme. Todos os obstáculos existentes foram transpostos e, para tanto, contamos com o estímulo de nosso orientador, Celso Carlos de Campos Guerra, e do exemplo da incansável luta encetada durante todos este anos por Paulo César Naoum em divulgar as hemoglobinopatias hereditárias mais freqüentes em nossa população.

A visão social das hemoglobinopatias hereditárias, mais especificamente a anemia falciforme, assumiu caráter de doença de saúde pública e, para tanto, demonstramos a necessidade dela assim ser encarada.

Através de dados existentes em todo o mundo, e pelas características do nosso povo, postulamos a prevenção, orientação e a organização de programas de detecção de hemoglobinopatias hereditárias em berçários, maternidades e em medicina ocupacional".

Esta reprodução de 25 anos atrás divulga o pensamento do editor sobre o tema, em 1985, e que não se modificou; tem o propósito de expor aos leitores parte dos anseios da época, em que a perspectiva de vida dos pacientes era restrita e não ultrapassava as duas décadas. Não havia, também, tratamento de suporte e de chance de melhoria na qualidade de vida dos pacientes e, principalmente, possibilidade de cura, hoje factível, a determinados pacientes selecionados com o transplante de células-tronco hematopoéticas.

Finalizando, a Revista Brasileira de Hematologia e Hemoterapia, com mais este fascículo, cumpre o seu objetivo de educar, disseminar informações e orientações sobre um tema relevante e de importância para saúde pública do país. 


\section{Referências Bibliográficas}

1. Hodenpyl E. A case of apparent absence of the spleen , with general compensatory lymphatic hyperplasia in Sergeant G, Sergeant B. Sickle cell before Herrick. Letter, Lancet. 1976;746.

2. Herrick JB. Peculiar elongated and sickle shaped red blood corpuscles in a case of severe anemia. Arch Intern Med. 1910;6:517.

3. Nell JV. The clinical detection of the genetic carriers of inherited disease. Medicine. 1947;26:115.

4. Accioly J. Anemia falciforme. Arq. Univ. Bahia. 1947;1:169.

5. Azevedo E. Historical note on inheritance of sickle cell anemia Jesse Accioly. The Am. J. Human Genetic. 1973;457.

6. Boturão E, Boturão E. Incidência de drepanocitose na Santa Casa de Santos, Seara Médica. 1952;6:447.

7. Araújo JT. Hemoglobinas anormais em S. Paulo. Métodos de Estudo. Incidência. J Bras. Med. 1965;9:1264.

8. Zago MA, Costa FF, Freitas TC, Bottura C. Clinical hematological and genetic features of sickle cell anemia and sickle cell beta thalassemia in a brazilian population. Clinical Genetics. 1980; 18:58.

9. Ramalho AS. Estudo médico dos polimorfismos genéticos de importância clínica no Brasil. Tese de Livre-docência, Universidade Estadual de Campinas - Unicamp, 1979.

10. Naoum PC. Hemoglobinopatias no Estado de S. Paulo, Tese de Livredocência, Unesp, Ibilce - São José do Rio Preto, S. Paulo. 1982.

11. Ruiz MA. Prevalência de hemoglobinas anormais em recém-nascidos na cidade de Santos, São Paulo. Tese de mestrado, Escola Paulista de Medicina, Unifesp, São Paulo, 1985 .

Editor da Revista Brasileira de Hematologia e Hemoterapia.

Correspondência: Milton Arthur Ruiz

Rua Profa. Carolina Ribeiro 165/112 - Vila Mariana

Chácara Klabim

04516-020 - S.Paulo-SP - Brasil

milruiz@yahoo.com.br

\section{A doença falciforme no Brasil Sickle cell disease in Brazil}

\author{
Rodolfo D. Cançado
}

Joice A. Jesus ${ }^{2}$

Há mais de trinta anos, os segmentos sociais organizados de homens e mulheres negras no Brasil vêm reivindicando o diagnóstico precoce e um programa de atenção integral às pessoas com doença falciforme (DF).

O primeiro passo rumo à construção de tal programa foi dado com institucionalização da Triagem Neonatal no Sistema Único de Saúde do Brasil, por meio da Portaria do Ministério da Saúde de 15 de janeiro de 1992, com testes para fenilcetonúria e hipotireoidismo congênito (Fase 1). Em 2001, mediante a Portaria nº 822/01 do Ministério da Saúde, foi criado o Programa Nacional de Triagem Neonatal (PNTN), incluindo a triagem para as hemoglobinopatias (Fase 2).

A inclusão da eletroforese de hemoglobina nos testes de triagem neonatal representou um passo importante no reconhecimento da relevância das hemoglobinopatias como problema de Saúde Pública no Brasil e também o início da mudança da história natural da doença em nosso país. Ao incluir a detecção das hemoglobinopatias no Programa Nacional de Triagem Neonatal, essa portaria corrigiu antigas distorções e trouxe vários benefícios, sobretudo a restauração de um dos princípios fundamentais da ética médica, que é o da igualdade, garantindo acesso igual aos testes de triagem a todos os recém-nascidos brasileiros, independentemente da origem geográfica, etnia e classe socioeconômica.

Configurando uma fase de consolidação dessa iniciativa, em 16 de agosto de 2005 foi publicada a Portaria de $n^{\circ}$ 1.391, que institui, no âmbito do SUS, as diretrizes para a Política Nacional de Atenção Integral às Pessoas com Doença Falciforme e outras Hemoglobinopatias. ${ }^{1}$

No momento, o Ministério da Saúde, através da Coordenação Geral da Política Nacional de Sangue e Hemoderivados, vem trabalhando na regulamentação e na implantação das medidas estabelecidas pela Portaria 1.391, bem como na organização da rede de assistência às pessoas com outras hemoglobinopatias em todos os estados da União.

A anemia falciforme é a doença hereditária monogênica mais comum do Brasil, ocorrendo, predominantemente, entre afro-descendentes.

A distribuição do gene S no Brasil é bastante heterogênea, dependendo de composição negróide ou caucasóide da população. Assim, a prevalência de heterozigotos para a Hb S é maior nas regiões norte e nordeste (6\% a 10\%), enquanto nas regiões sul e sudeste a prevalência é menor (2\% a 3\%).

O Quadro 1 e a Figura 1 mostram os principais dados da DF no Brasil segundo o Ministério da Saúde do Brasil. Estima-se o nascimento de uma criança com anemia falciforme para cada mil recém-nascidos vivos. 